\title{
Pressure-Relief Mechanism and Application of Large-Diameter Boreholes in Coal Seams with Rockburst Hazard
}

\author{
Zhen Hao $\mathbb{D}^{1,2}$ Guangzhong Sun, ${ }^{1}$ Haihang Wei, ${ }^{1}$ Jiayu Liu, ${ }^{1}$ Maolin Tian, ${ }^{1}$ Shuaiyi Liu, ${ }^{1}$ \\ and Yikun $\mathrm{Xu}^{1}$ \\ ${ }^{1}$ School of Resources and Safety Engineering, Henan University of Engineering, Zhengzhou 451191, China \\ ${ }^{2}$ State and Local Joint Engineering Laboratory for Gas Drainage \& Ground Control of Deep Mines, Henan Polytechnic University, \\ Jiaozuo 454003, China
}

Correspondence should be addressed to Zhen Hao; haozhen09@163.com

Received 19 July 2021; Accepted 24 September 2021; Published 7 October 2021

Academic Editor: Haiyan Wang

Copyright (c) 2021 Zhen Hao et al. This is an open access article distributed under the Creative Commons Attribution License, which permits unrestricted use, distribution, and reproduction in any medium, provided the original work is properly cited.

\begin{abstract}
Drilling of large-diameter boreholes is regarded as an effective measure for rockburst prevention. By investigating the morphological characteristic and evolution of plastic zone in borehole surrounding rock, the pressure-relief mechanism of large-diameter borehole was ascertained, and the engineering application of large-diameter boreholes was assessed in the 13230 working face of Gengcun Coal Mine, Henan Province, China. The results showed that (1) the plastic zone in surrounding rock of borehole appear as circular, elliptical, and butterfly shapes, in which the maximum size of the butterfly wings of the plastic zone is several times larger than the borehole diameter; (2) under certain stress conditions, multiple large-diameter boreholes distributed in coal seam with rockburst risk lead to the generation and coalescence of large-range butterfly-shape plastic zone. They reduce the stress concentration and capacity for storing elastic energy of coal seam, thus reducing the rockburst risk of the coal seam; (3) large-diameter boreholes significantly decrease the stress concentration in front of the 13230 working face and improve the stress environment in the head entry, promoting the safe mining of the working face.
\end{abstract}

\section{Introduction}

Rockburst is one of the major engineering disasters caused by the violent release of accumulated strain energy in deep underground projects [1]. This phenomenon is often accompanied with the ejection of rock fragments, which would directly threaten the safety of workers $[2,3]$.

In recent years, rockburst have become more serious due to the increasing mining intensity and depth. For a long time, rockburst prevention and control in coal mines, as one of major research topics on prevention and control of mine disasters, has attracted much interest among scholars and engineering technologists. In early studies, many scholars elaborated the causes of static and dynamic failure of coal and rock mass from different perspectives and formed many classical theories, such as energy theory, strength theory, stiffness theory $[4,5]$, burst proneness theory
[6], instability theory [7], and "three factors" theory [8]. With the introduction of interdisciplinary disciplines such as mathematics and mechanics into this research field, burst start-up theory [9], catastrophe theory, and chaos theory have been formed $[10,11]$.

At present, the consensus is that the stress concentration degree and accumulation capacity for elastic energy in coal and rocks can be artificially lowered to prevent and control the rockburst. The type of pressure-relief measures in coal seams mainly include coal-seam water infusion, deep-hole blasting, and pressure relief through large-diameter borehole. Due to some unique advantages such as convenient and fast construction and small disturbance, large diameter pressure-relief borehole has been widely used in many mines prone to rockburst in China as an effective and conventional measure for rockburst prevention [12]. In engineering practice, large diameter pressure-relief borehole was investigated 
in Yuejin Coal Mine, and more than 3100 boreholes were drilled along the haulage gateway in the coal body [13]. In order to reduce the influence of geo-stress distribution on safety mining near the fault areas, the large diameter borehole large diameter method was used to conduct in situ geo-stress measurements [14]. Therefore, investigation on the pressure-relief mechanism of large-diameter boreholes is of significance for further enriching the theory on rockburst prevention and control and promoting the safe and efficient working of mines prone to rockburst.

In terms of pressure-relief and rockburst-prevention mechanism and the effect evaluation of large-diameter boreholes, many scholars have conducted effective studies from different perspectives. Jia et al. [15] thought that the fundamental reason why large-diameter boreholes show the pressure-relief effect is that cracks around borehole propagate and coalesce, releasing the concentrated stress accumulating in coal seams; moreover, the pressure-relief effect of boreholes is directly proportional to the borehole diameter and depth while inversely proportional to the borehole spacing. Jiao et al. [16] suggested that largediameter boreholes distributed in coal seams may decrease the peak particle velocity in dynamic conditions velocity and degree of stress concentration and its extent in the rock surrounding a roadway subjected to dynamic loads and increase the attenuation length of the elastic energy, thus greatly decreasing the possibility of a rockburst in the roadway. To reduce the rockburst risk in large coal pillars, $\mathrm{Li}$ et al. [17] realized the passive transfer of the concentrated stress in large coal pillars by distributing large-diameter boreholes with reasonable depth and spacing. Xiao et al. [18] found that the area subject to stress-concentration on the floor is shifted to greater depth by distributing largediameter boreholes across the floor and increasing their diameter. In this way, the range of the stress-drop zone is expanded, and the rockburst risk in the roadway floor is decreased. By further exploring the pressure-relief mechanism afforded by boreholes through the similar simulation tests, Qi et al. [19] found that the borehole diameter delivers a significant size effect on the pressure-relief effect and they provided a reasonable range of the borehole diameters acceptable to provision of pressure relief. By analyzing the pressure-relief effects of boreholes with different diameters through numerical simulation, Li et al. [20] showed that the borehole diameter is directly proportional to the pressure-relief effect, which is weakened when the spacing between boreholes for pressure relief exceeds some critical value. Zhu et al. [21] proposed to assess the residual hazard of pressure-relieved coal seams with rockburst hazard by using an energy dissipation index and proposed a method with which to quantify the parameters of large-diameter boreholes. Wei [22] suggested that the growth of the borehole diameter and depth can improve the pressure-relief effect of coal seams prone to rockburst. Many scholars have explored the failure mechanism of brittle hard rock drilling by means of laboratory experiments and numerical simulation and discussed the influence of drilling size, rock strength, load, and other parameters on the failure range of drilling [23-27]. However, the above research is only limited to sandstone or marble with high strength and rarely involved in coal with low strength drilling. The research results provide a basis for the present study.

By taking the specific engineering and geological conditions in Gengcun Coal Mine, Henan Province, China, as the research background, the rockburst-prevention mechanism of large-diameter boreholes was analyzed by studying the morphological characteristics and evolution of plastic zone in the borehole surrounding rock based on the butterflyshape plastic zone theory. In addition, an engineering case study was performed.

\section{Pressure-Relief Mechanism of Large- Diameter Borehole}

2.1. The Formation Mechanism and Morphological Characteristic of Plastic Zone of Large-Diameter Borehole Surrounding Rock. The construction of large-diameter boreholes in coal seam is similar to the layout of a small roadway [28]. After excavating a roadway or drilling a borehole in coal and rocks, the stress in the surrounding rock of the roadway or borehole is redistributed, and plastic zone appear in the shallow part of the surrounding rock. Therefore, it is feasible to establish a mechanical model (Figure 1) for the surrounding rock of borehole in a nonconstant stress field by taking the zone with borehole with a radius of $a$ (generally being five times the borehole radius) as the separator. The loads on the boundary of the model are determined as $P_{1}$ and $P_{3}$.

The equation for the boundary of the plastic zone in surrounding rock of circular borehole in nonuniform stress field conditions derived according to literature [29] is described as follows:

$$
\begin{aligned}
& 9\left(1-\frac{P_{1}}{P_{3}}\right)^{2}\left(\frac{a}{r}\right)^{8}+\left[-12\left(1-\frac{P_{1}}{P_{3}}\right)^{2}+6\left(1-\frac{P_{1}^{2}}{P_{3}^{2}}\right) \cos 2 \theta\right]\left(\frac{a}{r}\right)^{6} \\
& +\left[10\left(1-\frac{P_{1}}{P_{3}}\right)^{2} \cos ^{2} 2 \theta-4\left(1-\frac{P_{1}}{P_{3}}\right)^{2} \sin ^{2} \varphi \cos ^{2} 2 \theta-2\right. \\
& \left.\cdot\left(1-\frac{P_{1}}{P_{3}}\right)^{2} \sin ^{2} 2 \theta-4\left(1-\frac{P_{1}^{2}}{P_{3}^{2}}\right) \cos 2 \theta+\left(1+\frac{P_{1}}{P_{3}}\right)^{2}\right]\left(\frac{a}{r}\right)^{4} \\
& +\left[-4\left(1-\frac{P_{1}}{P_{3}}\right)^{2} \cos 4 \theta+2\left(1-\frac{P_{1}^{2}}{P_{3}^{2}}\right) \cos 2 \theta-4\right. \\
& \left.\cdot\left(1-\frac{P_{1}^{2}}{P_{3}^{2}}\right)^{2} \sin ^{2} \varphi \cos 2 \theta-\frac{4 C\left(P_{3}-P_{1}\right) \sin 2 \varphi \cos 2 \theta}{P_{3}^{2}}\right]\left(\frac{a}{r}\right)^{2} \\
& +\left[\left(1-\frac{P_{1}}{P_{3}}\right)^{2}-\sin ^{2} \varphi\left(1+\frac{P_{1}}{P_{3}}+\frac{2 C \cos \varphi}{P_{3} \sin \varphi}\right)^{2}\right]=0,
\end{aligned}
$$

where $C$ and $\varphi$ separately refer to the cohesion and internal friction angle of the borehole surrounding rock; $r$ and $\theta$ separately represent the polar coordinates of the boundary of the plastic zone in the borehole surrounding rock; $a$ stands for the radius of the borehole; and $P_{1}$ and $P_{3}$ denote the loads on the boundary of the model. 


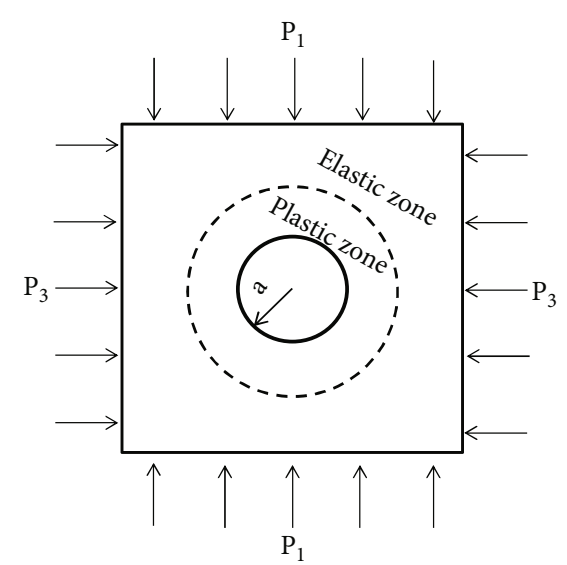

FIGURE 1: The mechanical model for the surrounding rock of borehole in nonconstant stress field.

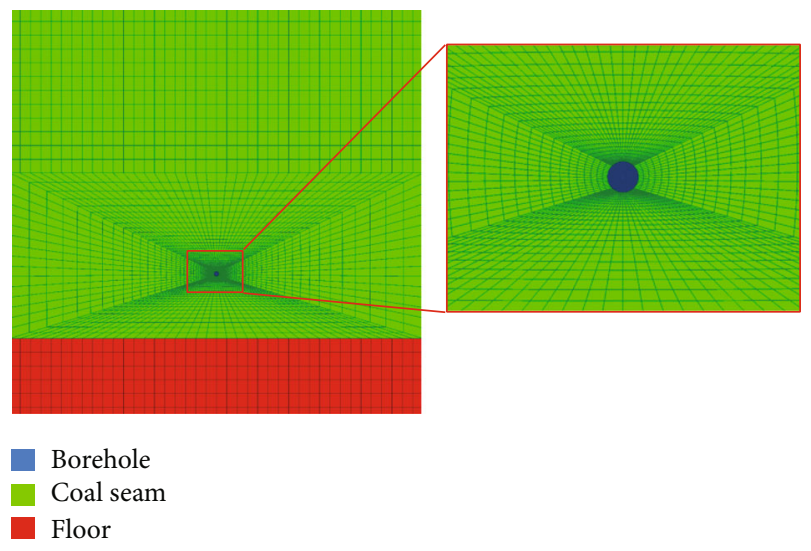

Figure 2: The numerical calculation model of borehole.

Therefore, the morphological characteristic and size of the plastic zone in the borehole surrounding rock depends on the stress field (that is, the bidirectional boundary load ratio $\left.P_{1} / P_{3}\right)$ of the boreholes and on fixed mechanical properties $(C$ and $\varphi)$ of the surrounding rock.

The morphological characteristics of the plastic zone in surrounding rock of the borehole were analyzed by numerical simulation method. A numerical calculation model (Figure 2) with dimensions of $40 \mathrm{~m} \times 40 \mathrm{~m} \times 1 \mathrm{~m}$ (length $\times$ width $\times$ thickness) was established, with the borehole diameter being $153 \mathrm{~mm}$. The displacements around the model in three directions $(x, y$, and $z)$ were fixed and that in the $y$-direction was fixed as for both the front and back boundaries. The immediate floor of the model exhibits consistent mechanical parameters with the coal seam, and the loads on the vertical and horizontal boundaries were separately set to $P_{1}$ and $P_{3}$. The mechanical parameters of coal seam and floor are shown in Table 1.

Under different stress conditions, the plastic zone morphological characteristics of borehole surrounding rock are obviously different (Figure 3). As shown in Figure 3, when the bidirectional boundaries load ratio $P_{1} / P_{3}$ is 1 , Figure 1 shows a mechanical model under bidirectional constant
TABLE 1: The mechanical parameters of coal seam and floor.

\begin{tabular}{lcccr}
\hline Lithology & $\sigma_{\mathrm{c}} / \mathrm{MPa}$ & $\sigma_{\mathrm{t}} / \mathrm{MPa}$ & $C / \mathrm{MPa}$ & $\varphi /^{\circ}$ \\
\hline Coal seam and floor & 26 & 1.3 & 3 & 25 \\
\hline$\sigma_{\mathrm{c}}$ : compressive strength; $\sigma_{\mathrm{t}}$ : tensile strength; $C$ : cohesion; $\varphi$ : friction angle.
\end{tabular}

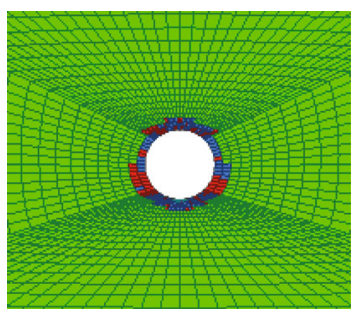

(a)

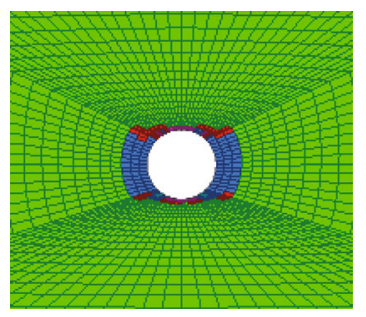

(b)

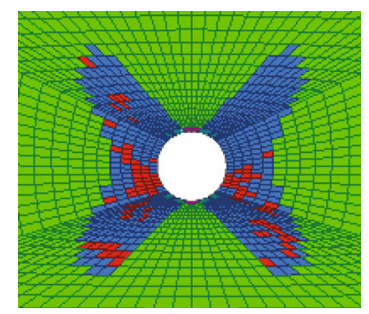

(c)

FIgURE 3: The plastic zone morphological characteristics of borehole surrounding rock under different stress conditions.

stress field, and Equation (1) for the boundary of plastic zone in borehole surrounding rock is the standard equation for circle. In this case, the boundary of the plastic zone is circular (Figure 3(a)). When $P_{3}$ remains unchanged and $P_{1} / P_{3}$ increases to 1.7 , the boundary in the horizontal direction gradually broadens while that in the vertical direction becomes narrower. The maximum and minimum radii of the boundary of the plastic zone separately occur in the transverse and longitudinal axes, and the boundary of the plastic zone becomes ellipse-like in shape (Figure 3(b)). When $P_{1} /$ $P_{3}$ reaches 2.5 , the profile of the plastic zone boundary is concave at coordinate axes while protrudes in four quadrants, thus appearing as a butterfly shape (Figure 3(c)). Moreover, the maximum radius of the boundary of butterfly-shape plastic zone occurs in the vicinity of the angular bisector of the included angle between coordinate axes.

\subsection{The Pressure-Relief Mechanism of Large- Diameter Borehole}

2.2.1. Evolution of Plastic Zone of Large-Diameter Borehole. According to the literature [30], Figure 4 shows the morphological characteristics of the plastic zone around boreholes with different distances to the 13230 working face in Gengcun Coal Mine when the working face is advanced by $30 \mathrm{~m}$, and the borehole diameter is $153 \mathrm{~mm}$.

As shown in Figure 4, at different distances to the working face, both the maximum and minimum principal stresses differ as do the morphological characteristics and range of 


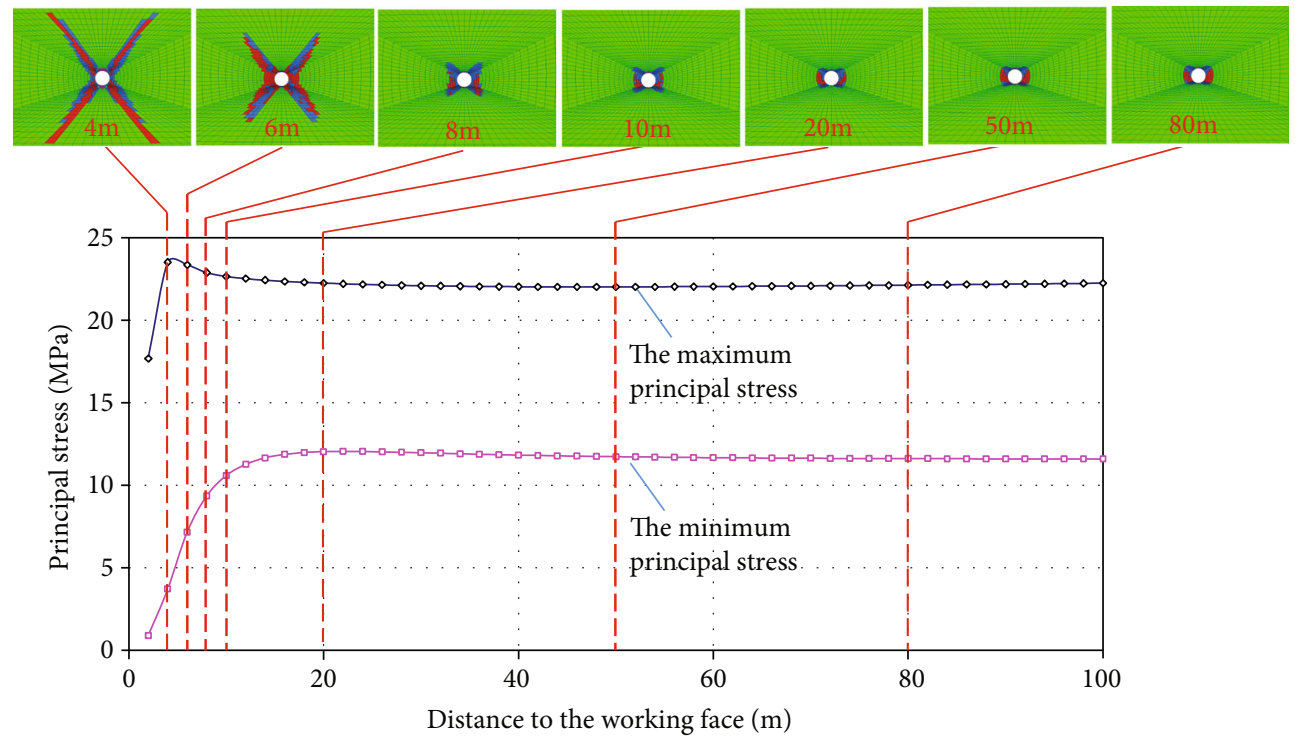

Figure 4: Evolution of the plastic zone around large-diameter boreholes.

the plastic zone around the large-diameter boreholes. In the range of $100 \mathrm{~m}$ from the working face, the plastic zone of the surrounding rock is elliptic and butterfly shape influenced by mining stress, and the smaller the distance to the working surface, the larger the size of plastic zone. At a position to the working face not lower than $20 \mathrm{~m}$, the ratio of the maximum principal stress to the minimum principal stress is about 1.9, and the plastic zone is distributed in an elliptical shape, with the maximum radius occurring along the transverse axis.

The plastic zone around four shoulder angles of a borehole extend outwards at a position $10 \mathrm{~m}$ from the working face. With decreasing distance from the working face, the ratio of the maximum principal stress to the minimum principal stress gradually rises, and the boundary of the plastic zone in vertical and horizontal directions varies (albeit only slightly). The maximum size of the plastic zone gradually extends to the deep part along the angular bisector of the included angle between coordinate axes, and the plastic zone gradually evolves into a butterfly shape. At positions $4 \mathrm{~m}$ and $6 \mathrm{~m}$ from the working face, the maximum sizes of the butterfly wings of plastic zone are $0.91 \mathrm{~m}$ and $0.65 \mathrm{~m}$, which are 11.9 and 8.5 times of the borehole radius.

2.2.2. The Pressure-Relief Mechanism of Large-Diameter Borehole. When constructing large-diameter boreholes in coal seam with rockburst hazard, a certain range of plastic zone is generated after coal around the boreholes is subjected to mining stress. Under certain stress conditions, the maximum radius of the plastic zone of a single borehole can be several times larger than the borehole diameter. In the case that large range plastic zones are generated and coalesce around multiple large-diameter boreholes (Figure 5), the elastic energy accumulated in the coal seam is slowly released, and the peak stress reduced as well; thus, large pressure-relief areas are formed, and the area of stress

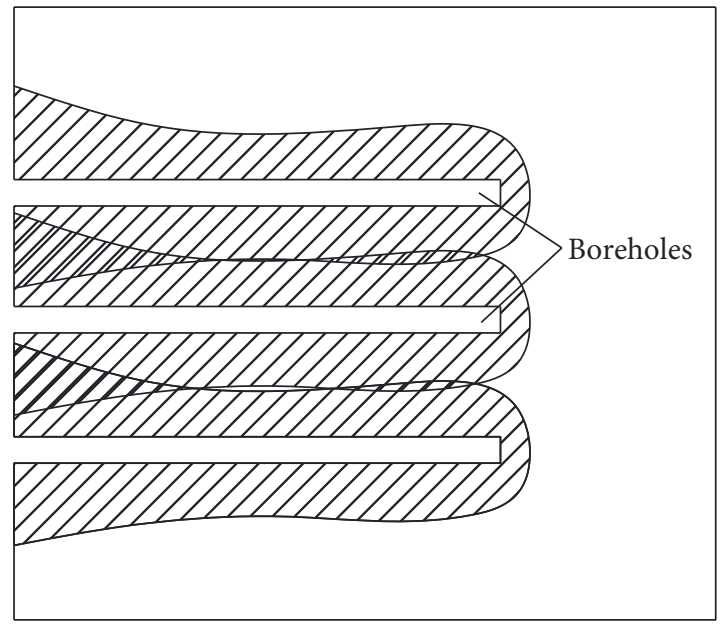

FIGURE 5: The pressure-relief principle of large-diameter boreholes.

concentration is shifted to greater depth in the coal seam. Therefore, in terms of the prevention and control of rockburst, the large-diameter borehole mainly function in two ways. One is relieving pressure, that is, the coalesced plastic zone around boreholes can alleviate the stress concentration and the rockburst hazard in coal seam. The other way is by changing the mechanical properties of coal seam, that is, the generation of plastic zone around boreholes weakens the capacity of coal seam to store elastic energy, thus decreasing the risk of rockburst $[15,31]$.

\section{Engineering Application}

3.1. Engineering Background. The Gengcun Coal Mine, located in the middle part of Yima Coalfield, Henan Province, China, is the main mine of Yima Coal Company, Henan Energy and Chemical Industry Group Co., Ltd. In the mine, the $2-3$ coal seam with a dip angle of $9^{\circ}$ to $13^{\circ}$ is 


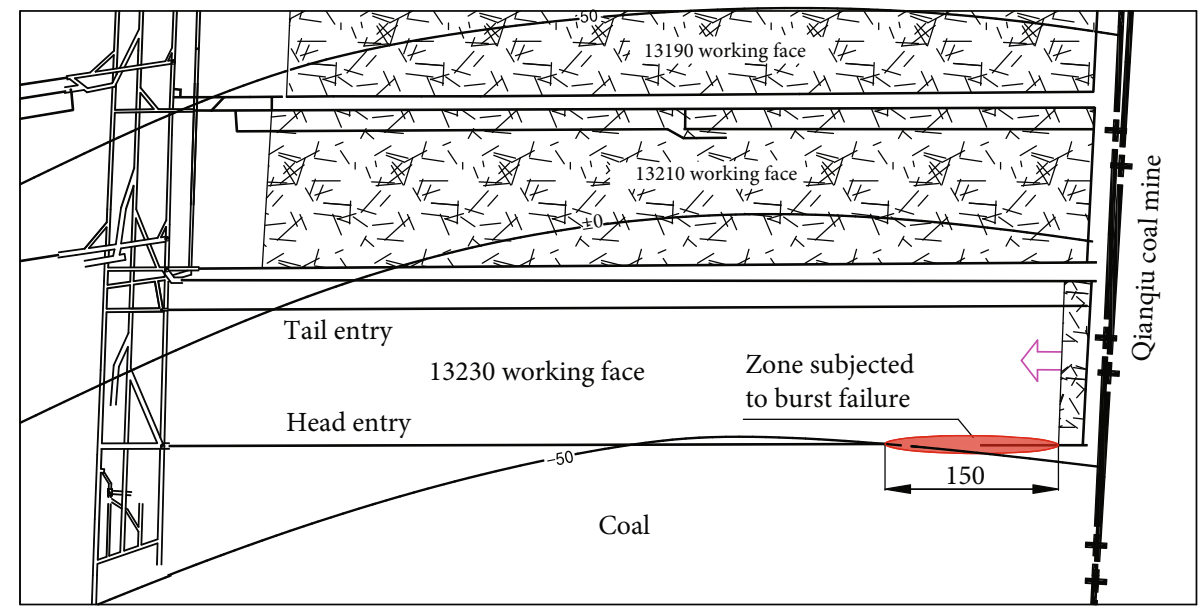

Figure 6: The layout of the working face of Gengcun Coal Mine.

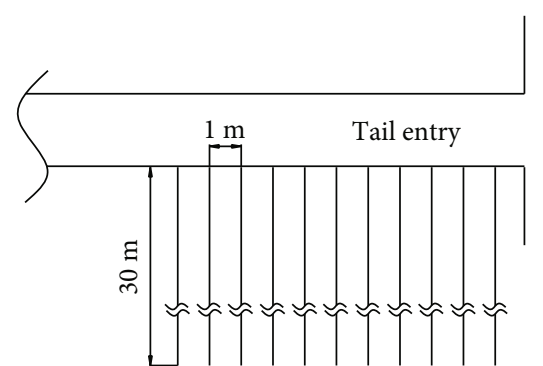

(a)

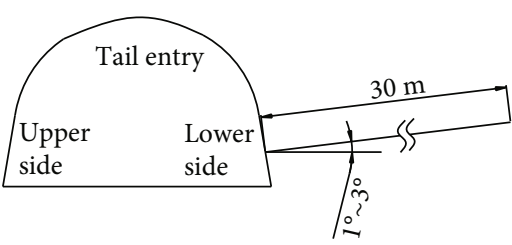

(b)

FIgURE 7: The layout of large-diameter boreholes drilled in tail entry. (a) The plan view of the large-diameter boreholes layout. (b) The crosssection of the layout of large-diameter boreholes.

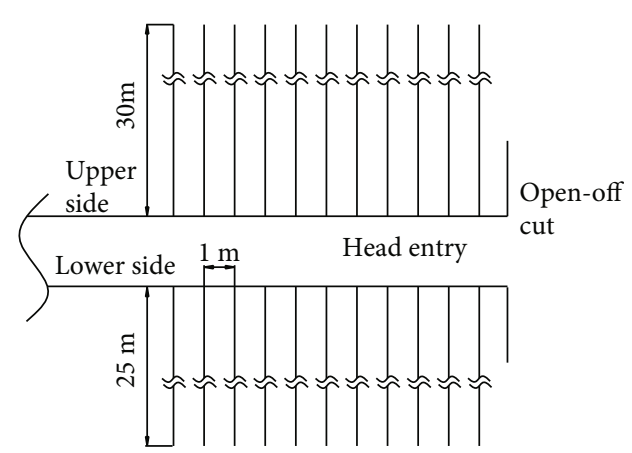

(a)

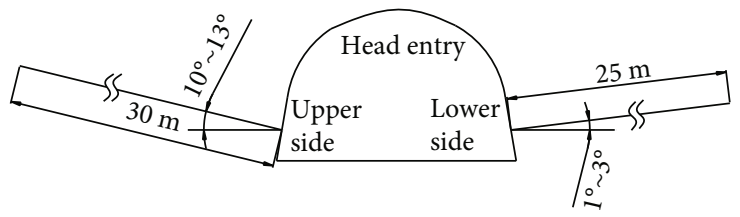

(b)

FIGURE 8: The distribution of large-diameter boreholes drilled in the head entry. (a) The plan view of the large-diameter boreholes layout. (b) The crosssection of the layout of large-diameter boreholes.

mainly mined, showing strong rockburst proneness. In December 2015, a severe rockburst accident happened in the head entry of the 13230 working face affected by the mining stress. It caused different degrees of burst failure in the roadway about $150 \mathrm{~m}$ in front of the working face of the head entry and led to casualties and economic loss. The layout of the working face is shown in Figure 6.

Both the crosssection of the head entry and tail entry of the 13230 working face appeared as a semicircular arch mea- suring $6.2 \mathrm{~m} \times 4.15 \mathrm{~m}$ (width $\times$ height). A coal pillar with the width of $8 \mathrm{~m}$ was set between the tail entry of the 13230 working face and the goaf of the adjacent 13210 working face.

\subsection{The Engineering Application of Large-Diameter} Boreholes for Pressure Relief. To reduce the risk of the burst failure occurring again in roadways during the mining of the 13230 working face, large-diameter boreholes were drilled 


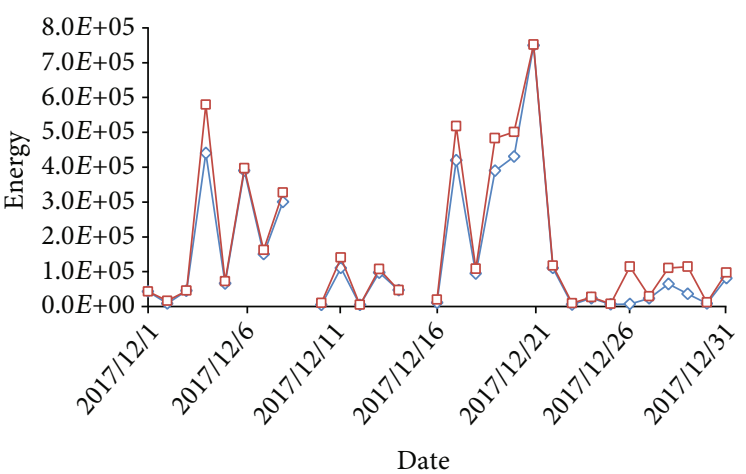

(a)

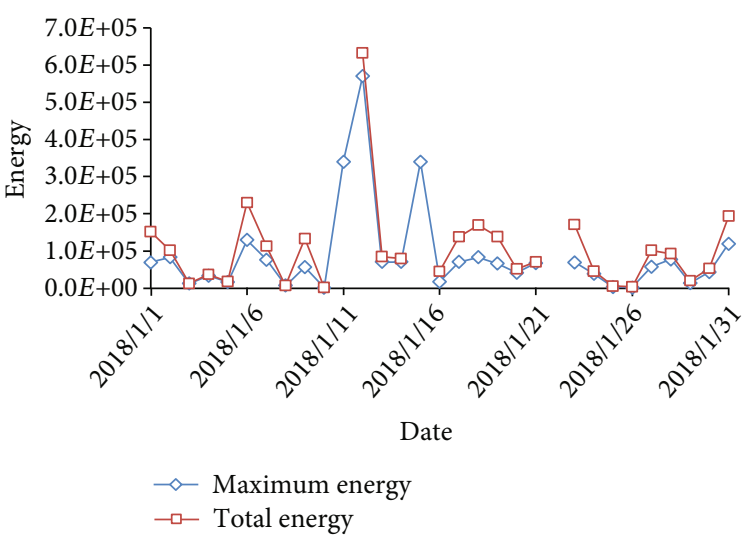

(b)

FIGURE 9: Curves of the energy and its frequency obtained based on MS monitoring. (a) MS monitoring data in December 2017. (b) MS monitoring data in January 2018.

from the lower side of the tail entry and upper and lower sides of the head entry within the range of $300 \mathrm{~m}$ ahead of the working face (as shown in Figures 7 and 8). To alleviate the stress concentration of the advanced abutment pressure on the working face, the depths of the large-diameter boreholes drilled from the lower side of the tail entry and the upper side of the head entry in the 13230 working face were no less than $30 \mathrm{~m}$ and that from the lower side of the head entry were no less than $25 \mathrm{~m}$. In addition, the dip angle of the large-diameter boreholes was adjusted (as appropriate) to guarantee that the boreholes were always distributed within coal, in which the dip angle of those boreholes drilled from the upper side of the head entry was within $10^{\circ}$ to $13^{\circ}$ and those from the lower side of the tail entry and the lower side of the head entry were between $1^{\circ}$ and $3^{\circ}$. Existing studies showed that the larger the borehole diameter, the better the pressure-relief effect; moreover, large-diameter boreholes were difficult to construct, resulting in a certain loss of construction efficiency [32]; therefore, according to the existing equipment and technical conditions, the diameter of the large-diameter boreholes for pressure relief in the 13230 working face was determined as $153 \mathrm{~mm}$, and the distance between the outlet of boreholes and the roadway floor was not less than $1 \mathrm{~m}$. To ensure coalescence of plastic zone around boreholes, the borehole spacing was set to $1 \mathrm{~m}$.

\subsection{Analysis of the Pressure-Relief Effect of Large- Diameter Boreholes}

3.3.1. In Situ Monitoring. After the resumption of production in the 13230 working face, multiple rockburst-prevention measures (such as pressure relief with large-diameter borehole and coal-seam water injection) were implemented in Gengcun Coal Mine, and a monitoring and warning system (involving microseismic (MS) event monitoring and drillcutting monitoring) was established.

Figure 9 shows MS event monitoring data from December 2017 to January 2018: the peak energy recorded reaches $10^{5} \mathrm{~J}$, and the maximum energy does not increase constantly

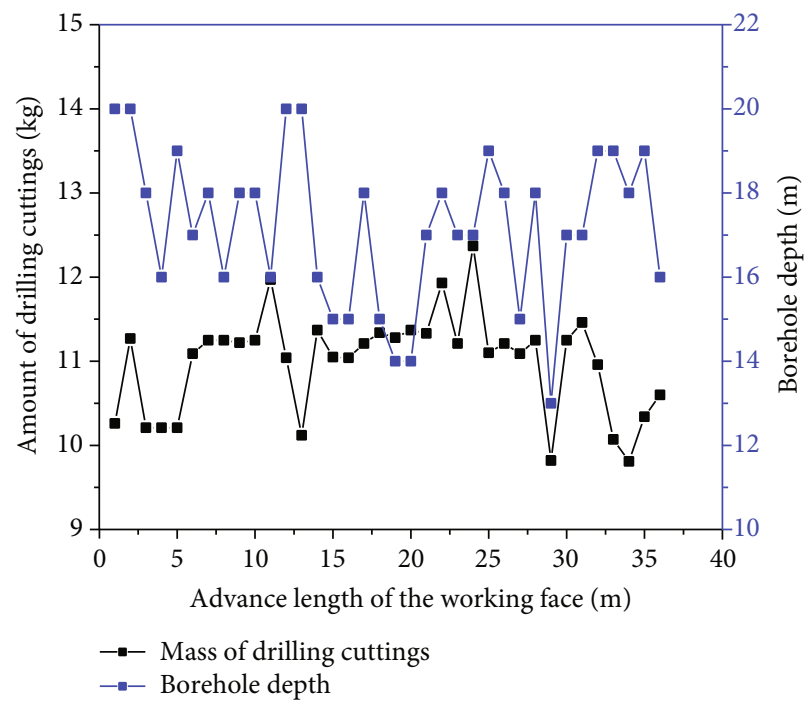

Figure 10: Monitored data of drill-cuttings.

TABLE 2: The critical mass of drill-cuttings to be monitored.

\begin{tabular}{lccccc}
\hline Borehole depth/m & $4 \sim 7$ & $7 \sim 10$ & $10 \sim 13$ & $13 \sim 16$ & $16 \sim 20$ \\
Critical mass $/ \mathrm{kg}$ & 8 & 11 & 17 & 23 & 29 \\
\hline
\end{tabular}

within 3 days. Through observation for two months, the maximum energy within each month was found to be $7.5 \times$ $10^{5} \mathrm{~J}$ and $5.7 \times 10^{5} \mathrm{~J}$, respectively.

During the mining of the 13230 working face, the advance length of the working face and the borehole depth and maximum amount of drill-cuttings monitored on each occasion (with a borehole diameter of $75 \mathrm{~mm}$ ) were recorded according to the preset monitoring range and various parameters such as the borehole depth and spacing.

The monitored results of the advance length of the working face and the maximum amount of drill-cuttings are shown in Figure 10: the 13230 working face was excavated 


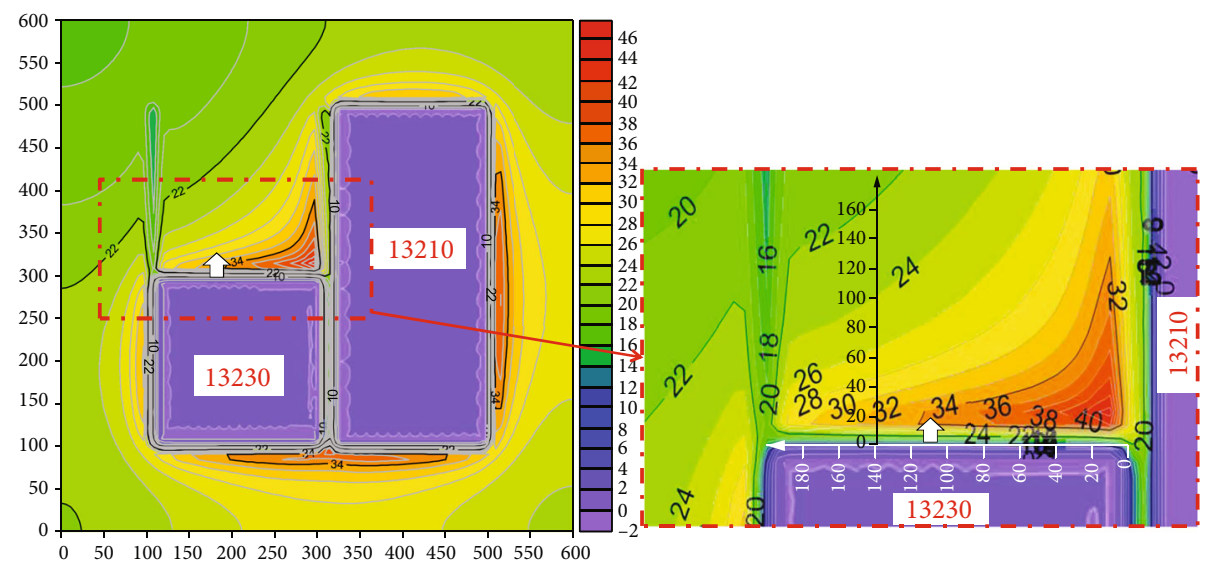

(a)

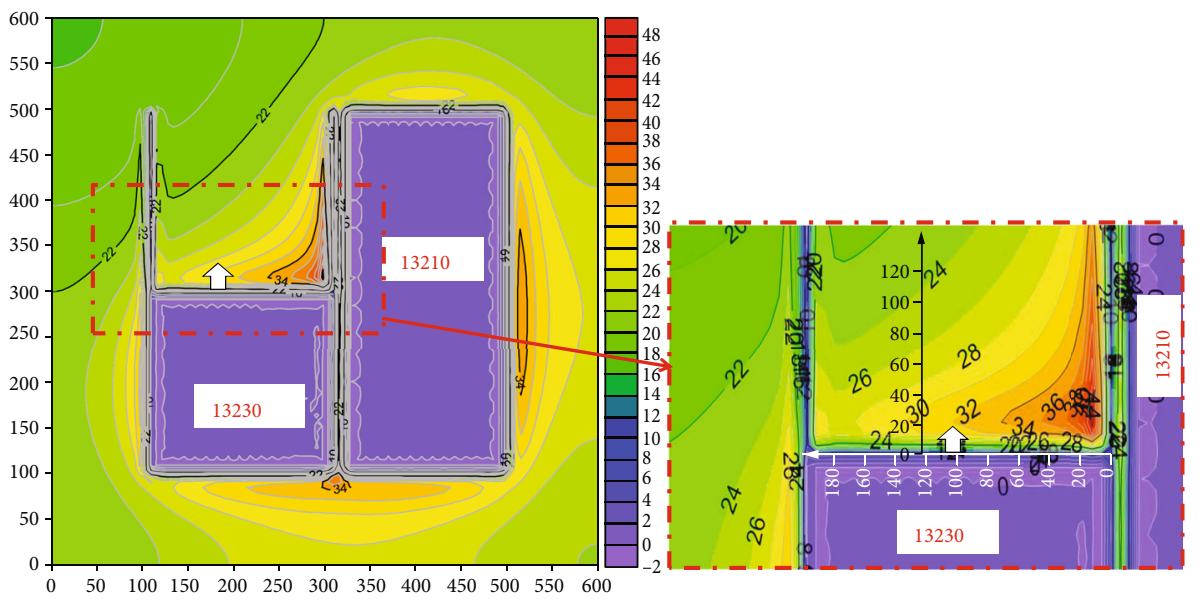

(b)

FiguRE 11: Distributions of vertical stress. (a) Without large-diameter boreholes. (b) With large-diameter boreholes.

for $36 \mathrm{~m}$ in total during the monitoring period; the amounts of drill-cuttings at different borehole depths were all lower than the critical value, showing insignificant fluctuations therein. The maximum amount of drilling cuttings was $12.37 \mathrm{~kg}$, which corresponded to a borehole depth of $17 \mathrm{~m}$, and it was much lower than the critical value (Table 2). Additionally, no burst failure appeared in the two roadways in the 13230 working face after resumption of production, allowing safe production from the mine.

3.3.2. Numerical Simulation Analysis. Before and after distributing large-diameter boreholes in segments ahead of the two roadways in the 13230 working face of Gengcun Coal Mine, the pressure-relief effect of large-diameter boreholes is compared in terms of the distribution of vertical stress in coal seam by way of numerical simulation. At first, a large numerical calculation model is established by FLAC $^{3 \mathrm{D}}$; afterwards, boreholes are excavated in the two roadways, and the 13210 and 13230 working face is mined in turn. Finally, the vertical stress on the roof of coal seam is extracted. Boundary conditions and other information about the numerical simulation analysis can be obtained from the literature [30]. After graphical postprocessing, the nephogram of the vertical stress is plotted (Figure 11).
As shown in Figure 9, the concentrated areas of vertical stress are found in front of the 13230 working face near the goaf of the 13210 working face both before and after distributing large-diameter boreholes in segments ahead of the head entry and tail entry in the 13230 working face. After large-diameter boreholes are drilled, the stress concentration in segments ahead of the head entry decreases to a significant extent. When large-diameter boreholes are not drilled to relieve this pressure, by taking the $34 \mathrm{MPa}$ contour as an example, the lengths of the contour along the dip the 13230 working face are about 120 (Figure 9(a)); after relieving pressure by constructing large-diameter boreholes, the lengths of the same contour $(34 \mathrm{MPa})$ along the dip of the 13230 working face are 70 (Figure 9(b)). Through comparison, it can be found that the distribution of large-diameter boreholes in two roadways can decrease the degree of stress concentration in front of the working face, thus improving the stress field around the head entry.

\section{Discussion}

As an effective measure for rockburst prevention, largediameter boreholes are widely used in coal seam with rockburst risk. Many scholars have studied the pressure-relief 
mechanism of large-diameter boreholes from different angles. In this paper, based on the plastic zone morphology of the surrounding rock of boreholes, it is considered that a large range of butterfly-shaped plastic zone will be produced and connected by several large-diameter boreholes in the coal seam under the mining pressure, so as to reduce the stress concentration degree of the coal seam and the capacity of storing elastic energy. Combined with the research results of existing literature, the research results of this paper will further enrich the prevention theory of rockburst and promote the safe and efficient mining of rockburst mines. In addition, there are still some limitations, such as butterfly shape plastic zone is formed in a certain surrounding rock and stress condition, and butterfly-shape plastic zone is directional, only when the butterfly wing and coal seam direction is consistent; the pressure relief effect of largediameter drilling is the best.

\section{Conclusion}

Through the systematic study on the pressure-relief mechanism of large-diameter boreholes and the engineering application, we mainly get the following conclusions.

(1) The plastic zone of borehole surrounding rock appeared in three forms, i.e., circular, elliptical, and butterfly shape. When the bidirectional boundaries load ratio reached a certain value, the length of the butterfly wings of a butterfly-shape plastic zone could be several times greater than the borehole diameter

(2) Under certain stress conditions, multiple largediameter boreholes drilled in coal seam with rockburst hazard induce the generation and coalescence of large-range butterfly-shaped plastic zone; moreover, they alleviate the stress concentration therein and capacity for storing elastic energy of coal seam, thus reducing the rockburst proneness of coal seam

(3) An engineering case study was analyzed based on the performance of two roadways in the 13230 working face of Gengcun Coal Mine. The results showed that the use of large-diameter boreholes can significantly decrease the degree of stress concentration in front of the working face and improve the stress field in the head entry, thus promoting the safe mining of the working face

\section{Data Availability}

The data used to support the findings of this study are available from the corresponding author upon request.

\section{Conflicts of Interest}

The authors declare no conflict of interest.

\section{Acknowledgments}

This work was partially supported by the Natural Science Foundation of China (Grant no. 52104126), the Key Scientific Research Project of Higher Education Institutions of Henan Province (Grant nos. 20A440002 and 21A440001), the Research Fund of State and Local Joint Engineering Laboratory for Gas Drainage \& Ground Control of Deep Mines (Henan Polytechnic University) (Grant no. SJF202008), and The Doctoral Cultivation Fund of Henan University of Engineering (Grant no. DKJ2019003).

\section{References}

[1] P. Leveille, M. Sepehri, and D. B. Apel, "Rockbursting potential of kimberlite: a case study of Diavik diamond mine," Rock Mechanics and Rock Engineering, vol. 50, no. 12, pp. 32233231, 2017.

[2] W. D. Ortlepp and T. R. Stacey, "Rockburst mechanisms in tunnels and shafts," Tunnelling and Underground Space Technology, vol. 9, no. 1, pp. 59-65, 1994.

[3] W. Z. Liang, B. Dai, G. Y. Zhao, and H. Wu, "A scientometric review on rockburst in hard rock: two decades of review from 2000 to 2019," Geofluids, vol. 2020, 17 pages, 2020.

[4] P. P. Procházka, "Application of discrete element methods to fracture mechanics of rock bursts," Engineering Fracture Mechanics, vol. 71, no. 4-6, pp. 601-618, 2004.

[5] L. M. Dou, C. P. Lu, Z. L. Mu, Y. H. Qin, and J. M. Yao, "Intensity weakening theory for rockburst and its application," Journal of China Coal Society, vol. 30, no. 5, pp. 690-694, 2005.

[6] S. V. Tsirel and N. V. Krotov, "Probability interpretation of indirect risk criteria and estimate of rock-burst hazard in mining anthracite seams," Journal of Mining Science, vol. 37, no. 3, pp. 240-260, 2001.

[7] M. T. Zhang, "Instability theory and mathematical model for coal/rock bursts," Chinese Journal of Rock Mechanics and Engineering, vol. 6, no. 3, pp. 197-204, 1987.

[8] Q. X. Qi and L. M. Dou, Theory and Technology of Rockburst, China University of Mining and Technology Press, 2008.

[9] J. F. Pan, Y. Ning, D. B. Mao, H. Lan, T. T. Du, and Y. W. Peng, "Theory of rockburst start-up during coal mine," Chinese Journal of Rock Mechanics and Engineering, vol. 31, no. 3, pp. 586596, 2012.

[10] Y. S. Pan and M. T. Zhang, "The study of coalburst by catastrophic theory," Journal of Fuxin Mining Institute, vol. 11, no. 1, pp. 12-18, 1992.

[11] S. H. Liu, "Nonlinear catastrophy model and chaotic dynamic mechanism of compound coal-rock unstable failure under coupled static-dynamic loading," Journal of China Coal Society, vol. 39, no. 2, pp. 292-300, 2014.

[12] S. C. Zhang, Y. Y. Li, B. T. Shen, X. Z. Sun, and L. Q. Gao, "Effective evaluation of pressure relief drilling for reducing rock bursts and its application in underground coal mines," International Journal of Rock Mechanics and Mining Science, vol. 114, pp. 7-16, 2019.

[13] Z. L. Li, L. M. Dou, W. Cai, G. F. Wang, Y. L. Ding, and Y. Kong, "Roadway stagger layout for effective control of gob-side rock bursts in the longwall mining of a thick coal seam," Rock Mechanics and Rock Engineering, vol. 49, no. 2, pp. 621-629, 2016. 
[14] M. Q. Huang, A. X. Wu, Y. M. Wang, and B. Han, "Geostress measurements near fault areas using borehole stress-relief method," Transactions of Nonferrous Metals Society of China, vol. 24, no. 11, pp. 3660-3665, 2014.

[15] C. Y. Jia, Y. J. Jiang, X. P. Zhang, D. Wang, H. J. Luan, and C. S. Wang, "Laboratory and numerical experiments on pressure relief mechanism of large-diameter boreholes," Chinese Journal of Geotechnical Engineering, vol. 39, no. 6, pp. 1115-1122, 2017.

[16] J. K. Jiao, W. J. Ju, and Y. Z. Wu, "Multi-layer control technologies for surrounding rock stability of dynamic-loading rock burst roadway," Coal Science and Technology, vol. 47, no. 12, pp. 10-17, 2019.

[17] D. Li, F. X. Jiang, Y. Chen, D. C. Gai, Y. Wang, and W. B. Wang, "Study on impact mechanism and prevention technology of drainage lane of large coal pillars near deep wells," Journal of Mining \& Safety Engineering, vol. 36, no. 2, pp. 265-271, 2019.

[18] Z. M. Xiao, J. Liu, H. Wang, L. Sun, and H. Zhou, "Study on mechanism and control of rock burst instability of roadway floor induced by dynamic load disturbance," Chinese Journal of Underground Space and Engineering, vol. 15, no. 5, pp. 1573-1581, 2019.

[19] Y. J. Qi, H. W. Jing, B. Meng, Z. X. Dong, and D. J. Liu, "Experimental modelling on size effect of pressure relief hole," Journal of Mining \& Safety Engineering, vol. 35, no. 3, pp. 538-544, 2018.

[20] Y. P. Li, H. W. Zhang, Z. J. Zhu, and C. Guo, "Study on safety parameters of pressure relief borehole in rockburst coal seam," China Safety Science Journal, vol. 28, no. 11, pp. 122-128, 2018.

[21] S. T. Zhu, F. X. Jiang, X. F. Shi et al., "Energy dissipation index method for determining rockburst prevention drilling parameters," Rock and Soil Mechanics, vol. 36, no. 8, pp. 2270-2276, 2015.

[22] H. C. Wei, “Technology and equipment of large diameter borehole construction applied to prevent and control pressure bump in coal mine," Coal Science and Technology, vol. 45, no. 10, pp. 140-143, 2017.

[23] Z. P. Ba Ant, F. Lin, and H. Lippmann, "Fracture energy release and size effect in borehole breakout," International Journal for Numerical and Analytical Methods in Geomechanics, vol. 17, no. 1, pp. 1-14, 1993.

[24] T. Meier, E. Rybacki, A. Reinicke, and G. Dresen, "Influence of borehole diameter on the formation of borehole breakouts in black shale," International Journal of Rock Mechanics and Mining Science, vol. 62, pp. 74-85, 2013.

[25] T. Meier, E. Rybacki, T. Backers, and G. Dresen, "Influence of bedding angle on borehole stability: a laboratory investigation of transverse isotropic oil shale," Rock Mechanics and Rock Engineering, vol. 48, no. 4, pp. 1535-1546, 2015.

[26] H. Lee, T. Moon, and B. C. Haimson, "Borehole breakouts induced in arkosic sandstones and a discrete element analysis," Rock Mechanics and Rock Engineering, vol. 49, no. 4, pp. 13691388, 2016.

[27] D. P. Sahara, M. Schoenball, E. Gerolymatou, and T. Kohl, "Analysis of borehole breakout development using continuum damage mechanics," International Journal of Rock Mechanics and Mining Science, vol. 97, pp. 134-143, 2017.
[28] Y. Han and F. Y. Zhang, "Progress in research on instability mechanism of coalbed borehole," Journal of Safety Science and Technology, vol. 10, no. 4, pp. 114-119, 2014.

[29] X. F. Yu, Y. R. Zheng, H. H. Liu, and Z. C. Fang, The Stability Analysis of Surrounding Rocks of Underground Engineering, China Coal Industry Press, 1983.

[30] H. T. Liu, Z. Hao, X. Y. Wu, X. D. Zhao, L. F. Guo, and Z. Y. $\mathrm{Ma}$, "Mechanism of blast disaster induced by instantaneous malignant expansion of plastic zone," Journal of China Coal Society, vol. 42, no. 6, pp. 1392-1399, 2017.

[31] J. Liu, Z. H. Ouyang, Q. X. Qi, S. K. Zhao, and X. L. Li, “Rigidflexibility integrated energy absorption support technology applied in deep mine with pressure bumping," Coal Science and Technology, vol. 41, no. 6, pp. 17-20, 2013.

[32] H. J. Liu, "Drilling pressure relief technology and effect of bilateral goaf island working face," Coal Engineering, vol. 48, no. 4 , pp. 58-61, 2016. 